\begin{abstract}
A breath of fresh air
Lancet 372, 2023-2030 (2008)

In June, doctors successfully replaced a damaged portion of a 30-year-old woman's windpipe with a section grown from her own cells. Claudia Castillo (right) had a 3-centimetre-long collapsed section in her left bronchus from a tuberculosis infection.

Paolo Macchiarini at the University of Barcelona in Spain and his colleagues extracted a stretch of windpipe from a deceased donor. They washed this 25

times over a six-week period to remove all of the donor's cells, leaving only the windpipe's extracellular structure, which they seeded with Claudia's stem cells and cells from the bronchial surface.

The bioengineered trachea was then transplanted, providing Castillo with immediate respiratory relief. It continues to work well.

IMMUNOLOGY

\section{Successful delivery}

Cell 134, 577-586 (2008)

Researchers for the first time reversed symptoms of HIV infection in a living animal using the technique of RNA interference. They constructed an antibody that targets T cells - in which HIV lurks - and linked it to a peptide carrying small RNA molecules, called siRNAs. The peptide helps these siRNAs enter T cells, where they silence certain host and virus genes crucial to the virus's replication.

Premlata Shankar, now at the Texas Tech University Health Sciences Center in El Paso, Sang-Kyung Lee of Hanyang University in Seoul, South Korea, and their colleagues

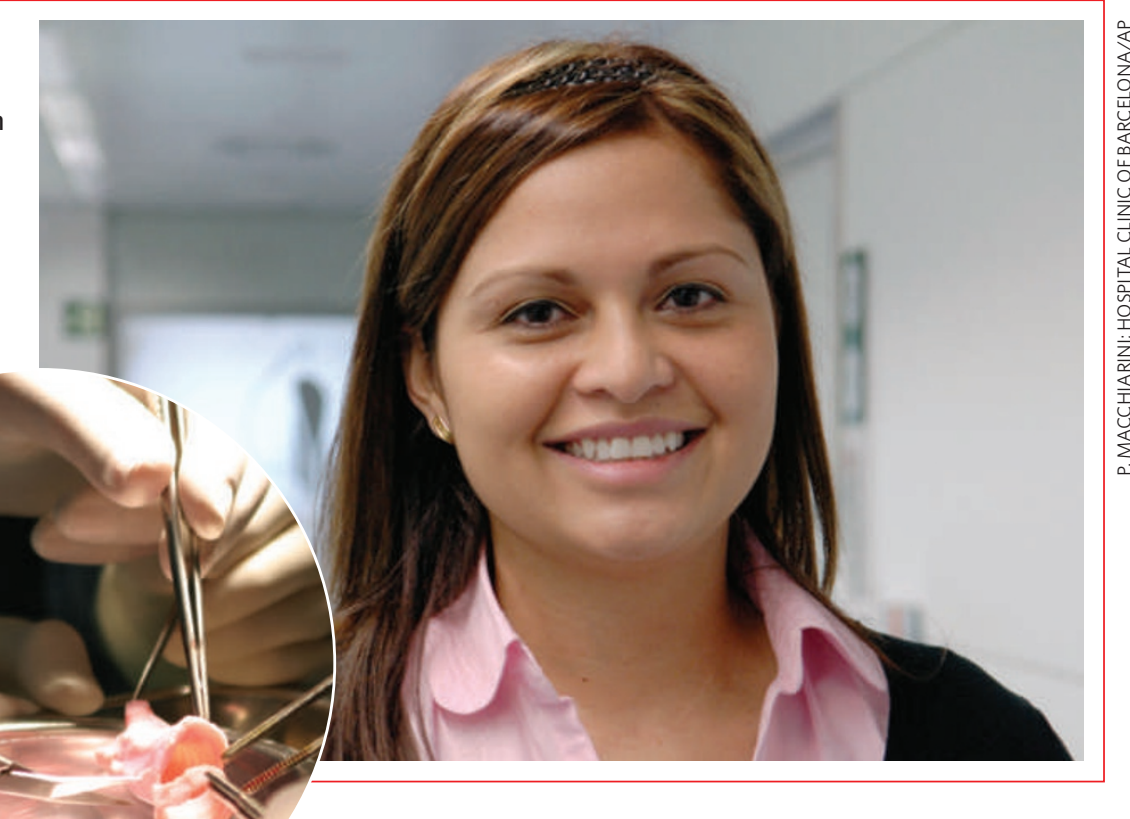

Such neurons are known as motor

When their shape is nearparabolic, they bounce light onto the secondaries, illuminating the holes in the primaries. When they are flat, no light hits the secondaries and the holes remain dark.

The prototype pixels transmit more than three times as much light as comparable liquid crystal displays. At present, the contrast they achieve is low, but models suggest that this can be improved. The technology may be suited to large, energyefficient flat panels.

\section{NEUROBIOLOGY}

\section{The motor-neuron driver}

neurons. In the spine, motor neurons that control muscles in different regions of the body segregate into columns. Jeremy Dasen and Thomas Jessell of Columbia University in New York and their colleagues found that the amount of FoxP1 present alters the proportions of the different column types that neurons form. Increasing the expression of FoxP1 in embryonic mouse and chick motor neurons, for example, led to more neurons in the columns that innervate muscles in limbs.

Meanwhile, removing the FoxP1 gene not only affected column diversity but also altered the connections among motor neurons in limbs, and the patterns of axons that project into individual muscles.
\end{abstract} injected the construct into mice genetically engineered to be easy to infect with HIV. The construct protected the mice from infection. It also restored the suppressed immune systems of mice that bore HIV-infected immune cells.

\section{PHOTONICS}

\section{Telescopic TV}

Nature Photon. 2, 492-495 (2008)

Telescopes often have a ring-shaped primary mirror to concentrate light onto a secondary mirror, which, in turn, reflects it through the hole in the primary. The same principle informs a new design for backlit screens.

In the 'telescopic pixels' described by Anna Pyayt of the University of Washington in Seattle and her team, the shape of the primary mirrors is under electronic control.
Cell 134, 304-316 (2008)

The diversity and direction of the nerve cells responsible for muscle movements are controlled by a protein called FoxP1, according to research published this year.

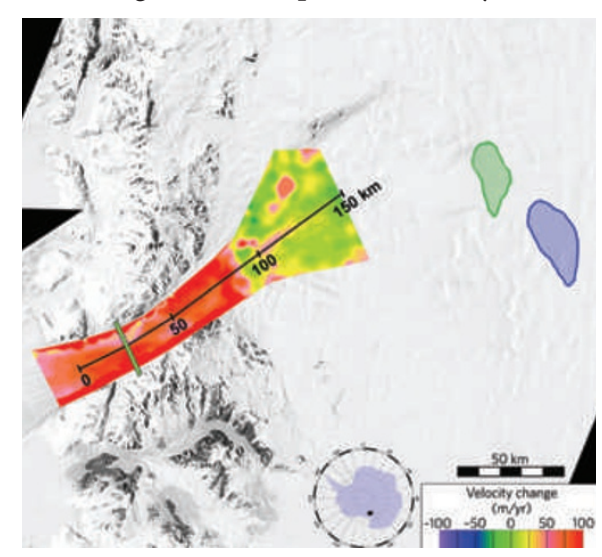

\section{GEOSCIENCE}

\section{The speed of ice}

Nature Geosci. 1, 827-831 (2008)

Until recently, lakes beneath glaciers were regarded as static things. But Leigh Stearns of the University of Maine in Orono and her colleagues discovered that the gain and loss of water in such lakes contributes to the movement of the ice they underlie.

The team correlated a $10 \%$ increase in the flow speed of the Byrd Glacier in Antarctica between December 2005 and February 2007 (pictured left) with satellite measurements showing a huge discharge of water from two subglacial lakes 200 kilometres upstream.

The lakes released about 1.7 cubic kilometres of water over roughly the same period, submerging spots at which the glacier was sticking and hence lubricating it. 